\title{
Hematology point of care testing and laboratory errors: an example of multidisciplinary management at a children's hospital in northeast Italy
}

This article was published in the following Dove Press journal: Journal of Multidisciplinary Healthcare

16 January 2014

Number of times this article has been viewed

\section{Sergio Parco \\ Patrizia Visconti \\ Fulvia Vascotto \\ Institute for Maternal and Child Health, Trieste, Italy}

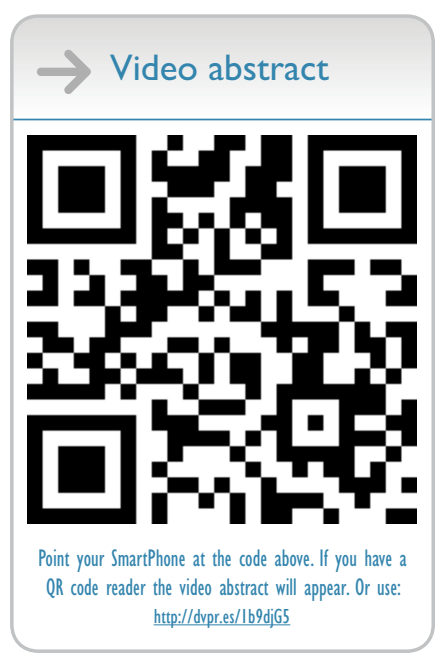

Correspondence: Sergio Parco Institute for Maternal and Child Health, Via dell'Istria 65/I, Trieste 34I37, Italy

Tel +390403785332

Fax +39040378 5210

Email parco@burlo.trieste.it

\begin{abstract}
Involvement of health personnel in a medical audit can reduce the number of errors in laboratory medicine. The checked control of point of care testing (POCT) could be an answer to developing a better medical service in the emergency department and decreasing the time taken to report tests. The performance of sanitary personnel from different disciplines was studied over an 18-month period in a children's hospital. Clinical errors in the emergency and laboratory departments were monitored by: nursing instruction using specific courses, POCT, and external quality control; improvement of test results and procedural accuracy; and reduction of hemolyzed and nonprotocol-conforming samples sent to the laboratory department. In January 2012, point of care testing (POCT) was instituted in three medical units (neonatology, resuscitation, delivery room) at the Children's Hospital in Trieste, northeast Italy, for analysis of hematochemical samples. In the same period, during the months of January 2012 and June 2013, 1,600 samples sent to central laboratory and their related preanalytical errors were examined for accuracy. External quality control for POCT was also monitored in the emergency department; three meetings were held with physicians, nurses, and laboratory technicians to highlight problems, ie, preanalytical errors and analytical methodologies associated with POCT. During the study, there was an improvement in external quality control for POCT from -3 or -2 standard deviations or more to one standard deviation for all parameters. Of 800 samples examined in the laboratory in January 2012, we identified 64 preanalytical errors (8.0\%); in June 2013, there were 17 preanalytical errors $(2.1 \%)$, representing a significant decrease $\left(P<0.05, \chi^{2}\right.$ test). Multidisciplinary management and clinical audit can be used as tools to detect errors caused by organizational problems outside the laboratory and improve clinical and economic outcomes.
\end{abstract}

Keywords: involvement, sanitary personnel, procedural accuracy, test results

\section{Introduction}

Laboratory testing is a highly complex process, and although laboratory services are relatively safe, they are not as safe as they could or should be. Clinical laboratories have long focused their attention on quality control methods and quality assessment programs dealing with the analytical aspects of testing. However, a growing body of evidence accumulated in recent decades demonstrates that quality in clinical laboratories cannot be assured by merely focusing on purely analytical aspects. ${ }^{1-5}$ More recent surveys of errors in laboratory medicine have concluded that mistakes occur more frequently before (preanalytical) and after (postanalytical) the test is performed. Rapid test reporting is particularly important in the emergency department. The risk 
of errors due to analytical problems has been significantly reduced over time, but there is evidence that carelessness may still have a serious impact on reporting. Mistakes made during the entire testing process are referred to as laboratory errors, although these may be due to haste or poor instruction and communication on the part of personnel, actions taken by others involved in the testing process (eg, physicians, nurses, phlebotomists, and laboratory technicians), or a poorly designed process, all of which are beyond the control of the laboratory. Constant turnover of staff in the emergency department and use of travelling nurses present a difficult challenge in terms of maintaining good practice. Further, there is evidence that laboratory information is often only partially utilized. ${ }^{6-8}$

Point of care testing (POCT) is a modern approach that could help to resolve some health care problems because it is centered on the needs and satisfaction of patients, particularly if laboratory departments have to provide a lot of test answers in a short space of time. This methodology is defined as medical testing at or near the site of patient care, to support timely, safe, and effective acute care (cardiac, metabolic, coagulation, respiratory distress). However, this strategy must be of the same standard as that in the central laboratory, and necessitates the involvement of more personnel from specialties outside the laboratory. ${ }^{9}$

In the changing landscape of the health care system, hospitals are becoming increasingly involved in the treatment of acute disease, and clinical laboratories have to increase their efficiency. Therefore, laboratory professionals, who are required to reduce costs, simplify processes, and decrease staff numbers, have considered the possibility of incorporating emergency testing into their routine work as a result of the improved productivity and flexibility of laboratory automation. In many situations, it is faster to perform both routine and emergency testing, with priority given to emergency testing, thereby simplifying laboratory processes and improving turnaround time. However, if the turnaround time does not satisfy physicians in the emergency department, the laboratory may need to take action to reduce the time interval between receiving requests and providing results. This improves clinical decision-making and patient management. The creation of large core laboratories as the centerpiece of pathology consortiums will increase the demand for POCT unless transport of specimens and information technology facilities are radically improved. ${ }^{10}$

This paper describes the most frequent and risky analytical errors, especially in the preanalytical phase, occurring at the Children's Hospital in Trieste, northeast Italy, related to the laboratory and emergency departments. The use of POCT as a modern pathology service involves information and instruction management about the importance to compare the test results with an external quality control. The purpose of this research was to demonstrate that meetings and audit processes involving sanitary personnel from both the laboratory and emergency departments can improve the performance of POCT and decrease the number of preanalytical laboratory errors.

\section{Materials and methods}

This work was conducted between January 2012 and June 2013, and involved sanitary personnel from three medical units (neonatology, resuscitation, delivery room) and technicians in the laboratory department. Studying this period of time, the preanalytical errors of tests sent to the laboratory department were examined. In the same period the emergency department was provided with three new POCT and the related external quality control of the analysis.

Three meetings were held with physicians, nurses, and laboratory technicians, to highlight two problems, ie, preanalytical errors and analytical methodologies used for POCT. For POCT in the emergency department, we used a hematology analyzer (Abacus Junior 30, Radiometer, Milan, Italy) to determine hemoglobin, hematocrit, mean corpuscular hemoglobin, mean corpuscular hemoglobin concentration, mean corpuscular volume, mean platelet volume, plateletcrit, platelets, red blood cells, red cell distribution, and white blood cells, and two blood gas instruments (ABL 800 FLEX, Radiometer, Milan, Italy) to analyze $\mathrm{pCO}_{2}, \mathrm{pH}, \mathrm{pO}_{2}$, calcium, chloride, glucose, lactate, potassium, and sodium. RIQAS reports from Randox Laboratories Ltd (Crumlin, UK) were used for external quality control. The $\chi^{2}$ test was used to test for a statistically significant difference between the number of preanalytical errors made at the beginning and end of the study. All members of the nursing staff signed a consent form to confirm their voluntary participation in the study, and accepted the methodology of the course, ie, objectives, teaching and learning methods, and expected outcome. This research had the approval of the bioethics committee at our institution.

\section{Results}

The core laboratory director provided weekly external quality control reports for POCT, and a review of preanalytical errors was undertaken. After 6 months, the laboratory director held the first meeting with sanitary personnel of the emergency and laboratory departments, to explain the 
problems identified and the methodology needed to solve these problems. At the end of the study, the results were forwarded to the medical units and key points were discussed (Tables 1-4).

Of 800 samples examined in the laboratory department in January 2012, we identified 64 preanalytical errors (8.0\%), classified as hemolysis, insufficient sampling, late arrival, not conforming to medical protocol, and without diagnosis; however, in June 2013, of 800 samples examined, only 17 preanalytical errors $(2.1 \%)$ were identified, representing a significant decrease $\left(P<0.05, \chi^{2}\right.$ test). During the study, there was an improvement in external quality control for POCT from -3 or -2 standard deviations or more to one standard deviation for all parameters.

In the emergency department setting, time is an important factor in the assessment, diagnosis, and stabilization of patients, and every effort should be made to save time when collecting laboratory specimens. Nurses often collect blood from an existing intravenous catheter to avoid a second venepuncture, thereby increasing efficiency and decreasing patient discomfort; however, increased hemolysis rates have been attributed to the practice of obtaining blood specimens in this way. Data collection points demonstrated that drawing

Table I Preanalytical errors in 800 examined samples sent to the central laboratory from the neonatology, resuscitation, and delivery room units from January 2012 to June 2013

\begin{tabular}{|c|c|c|c|c|}
\hline Analyte & $\begin{array}{l}\text { Mean for } \\
\text { comparison }\end{array}$ & $\begin{array}{l}\text { POCT } \\
\text { result }\end{array}$ & SDI & $\%$ DEV \\
\hline \multicolumn{5}{|c|}{ Hematology POCT of neonatology (January 20 I 2) } \\
\hline Hemoglobin & 5.995 & 6.200 & 1.32 & 3.4 \\
\hline Hematocrit (HCT) & 20.576 & 20.750 & 0.22 & 0.8 \\
\hline $\mathrm{MCH}$ & 27.958 & 30.700 & 2.25 & 9.8 \\
\hline $\mathrm{MCHC}$ & 29.184 & 30.000 & 0.65 & 2.8 \\
\hline MCV & 96.326 & 102.000 & 1.53 & 5.9 \\
\hline $\begin{array}{l}\text { Mean platelet volume } \\
\text { (pilot) }\end{array}$ & 9.167 & 8.700 & -0.74 & -5.1 \\
\hline Plateletcrit (pilot) & 0.040 & 0.030 & -1.78 & -24.9 \\
\hline $\begin{array}{l}\text { Platelets (impedance } \\
\text { count) }\end{array}$ & 47.500 & 32.000 & -3.55 & -32.6 \\
\hline $\begin{array}{l}\text { RBC (impedance } \\
\text { count) }\end{array}$ & 2.158 & 2.030 & -2.57 & -5.9 \\
\hline $\begin{array}{l}\text { Red cell dist width } \\
\text { CV (pilot) }\end{array}$ & 13.900 & 14.100 & 0.65 & 1.4 \\
\hline $\begin{array}{l}\text { Red cell dist width } \\
\text { SD (pilot) }\end{array}$ & 47.881 & No result & & \\
\hline $\begin{array}{l}\text { WBC (impedance } \\
\text { count) }\end{array}$ & 3.163 & 3.120 & -0.35 & -1.3 \\
\hline
\end{tabular}

Note: The difference between total errors at the start and end of the study (64 versus 17$)$ is statistically significant $(P<0.05)$. Bold figures depict alarm value. Abbreviations: $\mathrm{MCH}$, mean corpuscular hemoglobin; $\mathrm{MCHC}$, mean corpuscular hemoglobin concentration; RBC, red blood cells; SDI, standard deviation index; POCT, point of care testing; WBC, white blood cells; \% DEV, standard deviation percentage; dist, distribution; CV, coefficient of variation; SD, standard deviation.
Table 2 Confirmed improvement of external quality control in the neonatology unit from January 2012 to June 2013

\begin{tabular}{|c|c|c|c|c|}
\hline Analyte & $\begin{array}{l}\text { Mean for } \\
\text { comparison }\end{array}$ & $\begin{array}{l}\text { POCT } \\
\text { result }\end{array}$ & SDI & $\%$ DEV \\
\hline \multicolumn{5}{|c|}{ Hematology POCT of neonatology (June 2013) } \\
\hline Hemoglobin & $|3.74|$ & 14.300 & 1.85 & 4.1 \\
\hline Hematocrit (HCT) & 42.303 & 45.410 & 1.77 & 7.3 \\
\hline $\mathrm{MCH}$ & 29.572 & 30.100 & 0.46 & 1.8 \\
\hline $\mathrm{MCHC}$ & 32.889 & 31.400 & -1.10 & -4.5 \\
\hline MCV & 89.794 & 96.000 & 1.80 & 6.9 \\
\hline $\begin{array}{l}\text { Mean platelet volume } \\
\text { (pilot) }\end{array}$ & 10.586 & 9.600 & -1.56 & -9.3 \\
\hline Plateletcrit (pilot) & 0.213 & 0.240 & 1.13 & 12.8 \\
\hline $\begin{array}{l}\text { Platelets (impedance } \\
\text { count) }\end{array}$ & 225.778 & 250.000 & 1.50 & 10.7 \\
\hline $\begin{array}{l}\text { RBC (impedance } \\
\text { count) }\end{array}$ & 4.656 & 4.730 & 0.71 & 1.6 \\
\hline $\begin{array}{l}\text { Red cell dist width } \\
\text { CV (pilot) }\end{array}$ & 14.733 & 14.700 & -0.20 & -0.2 \\
\hline $\begin{array}{l}\text { Red cell dist width } \\
\text { SD (pilot) }\end{array}$ & & No result & & \\
\hline $\begin{array}{l}\text { WBC (impedance } \\
\text { count) }\end{array}$ & 9.398 & 9.120 & -0.71 & -3.0 \\
\hline
\end{tabular}

Abbreviations: $\mathrm{MCH}$, mean corpuscular hemoglobin; $\mathrm{MCHC}$, mean corpuscular hemoglobin concentration; RBC, red blood cells; SDI, standard deviation index (mean of comparison); POCT, point of care testing; WBC, white blood cells; \% DEV, standard deviation percentage; dist, distribution; CV, coefficient of variation, SD, standard deviation.

blood through an intravenous catheter was associated with hemolysis more frequently than using an intravenous catheter with a connected syringe. The principal problems identified were to do with transport of specimens, deviation from diagnostic protocols, and software programs used in the laboratory. Other observations noted by sanitary personnel included the finite staffing resources available in the emergency department and the high workload of staff caring for disabled pediatric and small for date neonatology patients, which can reduce the efficiency of certain procedures.

The most frequent and risky preanalytical errors were identified. Such problems were often due to poor communication, and action should be taken by all sanitary personnel involved in the testing (physicians, nurses, and phlebotomists in the laboratory and emergency departments) and transport process. In the collaborative approach to ensuring overall quality, the risk of errors and mistakes in laboratory testing must be minimized to guarantee the total quality of a laboratory service. ${ }^{11-16}$ Health personnel in the emergency department can affect tests in the laboratory, but nurses and doctors must be educated, given specific instructions, and complete courses on POCT. POCT data must be monthly controlled by laboratory quality control. The improvement in external quality control seen in this study demonstrates that nursing staff in the emergency department can provide 
Table 3 Confirmed improvement of external quality control in the resuscitation unit from January 2012 to June 2013

\begin{tabular}{|c|c|c|c|c|}
\hline Analyte & $\begin{array}{l}\text { Mean for } \\
\text { comparison }\end{array}$ & $\begin{array}{l}\text { POCT } \\
\text { result }\end{array}$ & SDI & $\%$ DEV \\
\hline \multicolumn{5}{|c|}{ Blood gas POCT of resuscitation unit (January 20 I2) } \\
\hline $\mathrm{pCO}_{2}$ & 18.987 & 19.200 & 0.25 & I.I \\
\hline $\mathrm{pH}$ & 7.521 & 7.527 & 0.21 & 0.1 \\
\hline $\mathrm{PO}_{2}$ & 143.084 & 152.000 & 0.45 & 6.2 \\
\hline Calcium & 0.848 & 0.861 & 0.27 & 1.5 \\
\hline Chloride & 119.313 & 119.300 & -0.00 & -0.0 \\
\hline Glucose & 249.288 & 264.000 & 0.49 & 5.9 \\
\hline Lactate & 0.985 & 1.000 & 0.12 & 1.5 \\
\hline Potassium & 6.635 & 6.730 & 0.56 & 1.4 \\
\hline Sodium & 155.476 & 155.700 & 0.10 & 0.1 \\
\hline \multicolumn{5}{|c|}{ Blood gas POCT of resuscitation unit (June 20I3) } \\
\hline $\mathrm{pCO}_{2}$ & 89.528 & 84.900 & -1.13 & -5.2 \\
\hline $\mathrm{pH}$ & 7.052 & 7.062 & 0.35 & 0.1 \\
\hline $\mathrm{PO}_{2}$ & 81.249 & 103.600 & 2.00 & 27.5 \\
\hline Calcium & 1.722 & 1.738 & 0.17 & 0.9 \\
\hline Chloride & 80.664 & 79.100 & -0.60 & -1.9 \\
\hline Glucose & 8.657 & 12.000 & 1.26 & 38.6 \\
\hline Lactate & 6.645 & 6.900 & 0.31 & 3.8 \\
\hline Potassium & 3.125 & 3.120 & -0.07 & -0.2 \\
\hline Sodium & 120.612 & 120.200 & -0.23 & -0.3 \\
\hline
\end{tabular}

Note: Bold figures depict alarm value.

Abbreviations: SDI, standard deviation index (mean of comparison); POCT, point of care testing; \% DEV, standard deviation percentage.

more efficient patient care. Their frequent execution, almost weekly, making sure data diagnostic process, can facilitate clinical decision, leading to a decrease in specimen recollection rates. It is important to improve specimen acceptability results in quicker laboratory results, to physicians who can have available the patient test report sooner; this positively affects patient outcomes in the emergency department. The study shows only a decrease in errors, but it does not ensure in general that appropriate therapies were given. POCT is not the solution to preanalytical nursing errors, but is important with regard to the needs of patients. ${ }^{17,18}$

\section{Discussion}

In the past, laboratory testing in Italy has been performed by physicians and laboratory technicians in a central laboratory, with some testing performed by "satellite" laboratories separate from the central laboratory, but still involving laboratory personnel. This is a historical model, different from that of the modern central laboratory. Attitudes concerning laboratory testing have changed significantly in the last few years and the economic problem of personnel cost imposes, in a modern approach, that technology POCT can be used by nurses at or near the site of patient care monitoring the patient without hospital admission. Maintaining the status quo (a central laboratory and other "satellite" laboratories)
Table 4 Confirmed improvement of external quality control in the delivery room from January 2012 to June 2013

\begin{tabular}{|c|c|c|c|c|}
\hline Analyte & $\begin{array}{l}\text { Mean for } \\
\text { comparison }\end{array}$ & $\begin{array}{l}\text { POCT } \\
\text { result }\end{array}$ & SDI & $\%$ DEV \\
\hline \multicolumn{5}{|c|}{ Blood gas POCT of delivery room (January 20I2) } \\
\hline $\mathrm{PCO}_{2}$ & 83.896 & 87.300 & 0.89 & 4.1 \\
\hline $\mathrm{pH}$ & 7.033 & 7.024 & -0.31 & -0.1 \\
\hline $\mathrm{pO}_{2}$ & 52.962 & 52.600 & -0.05 & -0.7 \\
\hline Calcium & 1.862 & 1.890 & 0.27 & 1.5 \\
\hline Chloride & 76.508 & 74.000 & -1.02 & -3.3 \\
\hline Glucose & 9.320 & 6.000 & -2.83 & -35.6 \\
\hline Lactate & 6.171 & 6.300 & 0.17 & 2.1 \\
\hline Potassium & 3.354 & 3.300 & -0.63 & -1.6 \\
\hline Sodium & 120.732 & 120.000 & -0.42 & -0.6 \\
\hline \multicolumn{5}{|c|}{ Blood gas POCT of delivery room (June 2013) } \\
\hline $\mathrm{pCO}_{2}$ & 18.128 & 17.700 & -0.52 & -2.4 \\
\hline $\mathrm{pH}$ & 7.535 & 7.540 & 0.17 & 0.1 \\
\hline $\mathrm{pO}_{2}$ & 141.878 & 157.000 & 0.78 & 10.7 \\
\hline Calcium & 1.060 & 1.110 & 0.86 & 4.7 \\
\hline Chloride & 120.833 & 122.000 & 0.30 & 1.0 \\
\hline Glucose & 251.294 & 246.000 & -0.18 & -2.1 \\
\hline Lactate & $0.84 I$ & 0.900 & 0.57 & 7.0 \\
\hline Potassium & 6.488 & 6.500 & 0.07 & 0.2 \\
\hline Sodium & |55.493 & 158.000 & 1.11 & 1.6 \\
\hline
\end{tabular}

Note: Bold figures depict alarm value.

Abbreviations: SDI, standard deviation index (mean of comparison); POCT, point of care testing; \% DEV, standard deviation percentage.

is not a good strategy for survival in laboratory medicine today. ${ }^{19-22}$ High-quality biological samples are needed, but are not sufficient alone for the quality of laboratory results. The total quality of a test is determined by control of analytical and preanalytical processes and by cooperation between laboratory technicians and other health care professionals, especially nurses. This is essential for reducing errors and for better analytical performance. Training protocols must be established and all potential operators must achieve an adequate level of competence. The content of the training program (including temperature, time, and modality of transportation to avoid contamination) and assessment of knowledge/skill levels should be documented in a training manual with a job description, that includes sample requirements, specimen collection, sample preparation, stability of reagents, and calibration of instruments. ${ }^{23,24}$

International guidelines and recommendations, along with procedures for quality and performance control, must also be approved and used for POCT in the emergency department. Laboratory medicine, like all health care, takes place in a dynamic, rapidly changing environment. As the standard of care changes, technology develops, and the economics of health care continue to change, the technology of POCT will be challenged to find new strategy. The economic benefits of POCT are proven when risk management concepts are applied. It means 
this approach to affront the clinical needs of the standard of care will be more used in the future. By understanding and considering POCT in the next future this concept may become aware of best way to meet the needs of medical care at residence (ie, management of coagulation therapy). ${ }^{25-27}$

Recognition of normal and abnormal results, as well as an understanding of the multidisciplinary action needed in the event of an abnormal result are essential. ${ }^{28-30}$ Faster is not always better, and in our experience POCT should be restricted to measurement of vital functions requiring an immediate response, eg, blood glucose, hemoglobin, and electrolytes (sodium, potassium, ionized calcium). ${ }^{31}$ The authors do not recommend introduction of POCT in the emergency department to solve the problem of inappropriate samples and inadequate transport to the laboratory department. However, collaboration and instruction of all sanitary personnel involved is essential to deal with preanalytical errors, performance of POCT, and external quality control, to maintain patient safety, and to improve risk management. The lack of studies like this can carry two other considerations, ie, the limits of a very expensive technology and the difficult in applying it, not only in the hospital but also at place of residence. ${ }^{32}$ Further studies and experience are necessary to resolve these questions.

\section{Disclosure}

The authors report no conflicts of interest in this work.

\section{References}

1. Whiting P, Rutjes AW, Reitsma JB, Bossuyt PM, Kleijnen J. The development of QUADAS: a tool for the quality assessment of studies of diagnostic accuracy included in systematic reviews. BMC Med Res Methodol. 2003;3:25.

2. Reitsma JB, Glas AS, Rutjes AW, Scholten RJ, Bossuyt PM, Zwinderman AH. Bivariate analysis of sensitivity and specificity produces informative summary measures in diagnostic reviews. J Clin Epidemiol. 2005;58:982-990.

3. Moses LE, Shapiro D, Littenberg B. Combining independent studies of a diagnostic test into a summary ROC curve: data-analytic approaches and some additional considerations. Stat Med. 1993;12:1293-1316.

4. Dinnes J, Deeks J, Kirby J, Roderick P. A methodological review of how heterogeneity has been examined in systematic reviews of diagnostic test accuracy. Health Technol Assess. 2005;9:109-113.

5. Blendon RJ, DesRoches CM, Brodie M, et al. Views of practicing physicians and the public on medical errors. N Engl J Med. 2002;347: 1933-1940.

6. Grant M. The effect of blood drawing techniques and equipment on the hemolysis of ED laboratory blood samples. J Emerg Nurs. 2003;29: 116-121.

7. Himberger JR, Himberger LC. Accuracy of drawing blood through infusing peripheral intravenous lines. Heart Lung. 2001;30:66-73.

8. Yoshikawa N. Hemolysis in serum samples drawn by emergency department personnel versus laboratory phlebotomists. Lab Med. 2002;33: $378-380$.
9. Cox S, Dages J, Jarjoura D, Hazelett S. Blood samples drawn from IV catheters have less hemolysis when 5-mL (vs 10-mL) collection tubes are used. J Emerg Nurs. 2004;30:529-533.

10. Price CP. Point of care testing. BMJ. 2001;322:1285-1288.

11. Landrigan CP, Parey GJ, Bones CB, et al. Temporal trends in rates of patient harm resulting from medical care. $N$ Engl J Med. 2010;363: 2124-2134.

12. Classen DC, Resar R, Griffin F, et al. "Global trigger tool" shows that adverse events in hospitals may be ten times greater than previously measured. Health Aff. 2011;30:581-589.

13. Berwick DM. The tension between needing to improve care and knowing how to do it. N Engl J Med. 2007;357:6608-6113.

14. Goods VS, Saldana M, Gilder R, et al. The science of improvement. J Am Med Assoc. 2008;299:1182-1184.

15. Thomas EJ, Petersen LA. Large-scale deployment of the "global trigger tool" across a large hospital system: refinements for the characterisation of adverse events to support patient safety learning opportunities. $B M J$ Qual Saf. 2011;20:25-30.

16. Thomas EJ, Petersen AA. Measuring errors and adverse events in health care. J Gen Intern Med. 2003;18:61-67.

17. Vincent C, Taylor Adams S, Stanhope N, et al. Framework for analysing risk and safety in clinical medicine. BMJ. 1998;316:1154-1157.

18. Morello RT, Lowthian JA, Barker AL, et al. Strategies for improving patient safety culture in hospitals: a systematic review. BMJ Qual Saf. 2013;22:11-18.

19. Ranji SR, Auerbach AD, Hurd CJ, et al. Effects of rapid response systems on clinical outcomes: systematic review and meta-analysis. J Hosp Med. 2007;2:422-432.

20. Chan PS, Jain R, Nallmothu BK, et al. Rapid response teams: a systematic review and meta-analysis. Arch Intern Med. 2010;170:18-26.

21. Ricòs C, Garcia-Victoria M, de La Fuente B. Quality indicators and specifications for the extra-analytical phases in clinical laboratory management. Clin Chem Lab Med. 2004;42:578-582.

22. Plebani M, Ceriotti F, Messeri G, et al. Laboratory network of excellence: enhancing patient safety and service effectiveness. Clin Chem Lab Med. 2006;44:150-160.

23. Jennings I, Kitchen DP, Woods TA, et al. Emerging technologies and quality assurance: the United Kingdom national external quality assessment scheme perspective. Semin Thromb Hemost. 2007;33: 243-249.

24. McCraw A, Hillarp A, Echenagucia M. Considerations in the laboratory assessment. Haemophilia. 2010;16 Suppl 5:74-78.

25. Kost GJ, Tran NK, Tuntideelert M, Kulrattanamaneeporn S, Peungposop N. Katrina, the tsunami, and point-of-care testing: optimizing rapid response diagnosis in disasters. Am J Clin Pathol. 2006;126:513-520.

26. Rossi AF, Khan D. Point of care testing: improving pediatric outcomes. Clin Biochem. 2004;37:456-461.

27. Kost GJ. Guidelines for point-of-care testing. Improving patient outcomes. Am J Clin Pathol. 1995;104 Suppl 1:S111-S127.

28. Tran NK, Kost GJ. Worldwide point-of-care testing: compendiums of POCT for mobile, emergency, critical, and primary care and of infectious diseases tests. Point of Care. 2006;5:84-92.

29. Lindenauer PK, Remus D, Roman S, et al. Public reporting and pay for performance in hospital quality improvement. $N \mathrm{Engl} \mathrm{J} \mathrm{Med.}$ 2007;356:486-496.

30. Chassin MR, Loeb J, Schmaltz SP, et al. Accountability measures-using to promote quality improvement. $N$ Engl J Med. 2010;363:683-688.

31. Lei G, Jixian Y, Xiannang S, Mei Y, et al. Three-dimensional paperbased electrochemiluminescence immunodevice for multiplexed measurement of biomarkers and point-of-care testing. Biomaterials. 2012;33:1024-1031.

32. Lee-Lewandrowski E, Lewandrowski K. Perspectives on cost and outcomes for point-of-care testing. Clin Lab Med. 2009;29:479-489. 


\section{Publish your work in this journal}

The Journal of Multidisciplinary Healthcare is an international, peerreviewed open-access journal that aims to represent and publish research in healthcare areas delivered by practitioners of different disciplines. This includes studies and reviews conducted by multidisciplinary teams as well as research which evaluates the results or conduct of such teams or

healthcare processes in general. The journal covers a wide range of areas and welcomes submission from practitioners at all levels, from all over the world. The manuscript management system is completely online and includes a very quick and fair peer-review system. Visit http://www.dovepress.com/testimonials.php to read real quotes from published authors.

Submit your manuscript here: http://www.dovepress.com/journal-of-multidisciplinary-healthcare-journal 